\title{
Moisture in walls before and after internal wall insulation: a long- term in-situ dataset
}

\author{
Naomi Grint ${ }^{1, *}$, Clifford A Elwell ${ }^{1}$ \\ ${ }^{1}$ UCL, Energy Institute, Central House, 14 Upper Woburn Place, London, United Kingdom
}

\begin{abstract}
This work addresses the need for long-term, high-resolution, in-situ datasets by providing in-wall humidity and temperature data from three walls of in-use office buildings over three to four years, two of which were insulated during this period. Temperature and humidity sensors were inserted diagonally into three locations within the thick brick walls, and the holes were carefully packed with dry brick dust. Surface, ambient and interstitial measurements were also recorded, as were additional climatic data during 18 months at one wall, and in-wall moisture content using resistance pins for 18 months in another. This dataset is unique due to the combination of temporal length and resolution, spatial detail, as well as the availability of control data from both before and after insulation and the use of real climatic conditions on both sides of the walls. The experiment was designed to produce data to facilitate parameter estimation by inverse analysis. By using these estimated parameters, or by taking material property measurements, it would also be useful for validating and calibrating hygrothermal models, and by using plausible ranges for parameters it is useful for exploring model performance, such as through sensitivity analyses.
\end{abstract}

\section{Introduction}

The climate emergency requires the significant reduction of carbon emissions associated with heating existing buildings, which is dependent on a large scale retrofit programme [1]. Insulating solid brick walls with internal wall insulation (IWI) is a key retrofit measure, but there is uncertainty around moisture risk, partly due to a lack of detailed measured data. This paper presents a four-year dataset that includes conditions pre and post IWI insulation, as well as a control wall. It is therefore useful for assessing the response to changes in environmental conditions of existing brick walls, and changes to the build-up, such as the addition of IWI. The number of measurement points through the walls, and the temporal resolution also provide the potential for parameter estimation by inverse analysis and, with these estimated material parameters or additional material property data, for exploring the performance of hygrothermal models.

Various studies have been undertaken to measure instructure moisture in different environments and at different resolutions. Examples include shorter, in-depth laboratory studies for validating heat and mass transfer models [2] and determining hygrothermal properties of small samples [3], and longer studies using a mix of laboratory and outdoor boundary conditions, for example in timber frame [4,5] and masonry walls [6]. Other studies assess walls in real in-situ environments with a broader assessment conditions post intervention [7, 8]. It is rare for a study using real environmental conditions to provide a dataset combining length and resolution, before and after conditions and a control wall.

\section{Experimental Design}

Three in-situ walls were identified for this study. Two in a building in East London with a planned internal wall insulation project, with one of the walls insulated in summer 2017 (A) and one left uninsulated (B). The uninsulated wall faces a large courtyard and is slightly more sheltered. Monitoring was undertaken for over one year before wall insulation was installed. The walls are approximately $50 \mathrm{~cm}$ thick and considered to be 'solid brick', although the inner wall and facing bricks are different types, and are separated by a mortar layer with voids in places. A third wall was identified at UCL Energy Institute $(\mathrm{C})$, which is a similar structure without the outer facing brick (a 'one and a half' brick English bond wall), and facing NNW, within $5^{\circ}$ of the other two walls. It was insulated in spring 2018. Monitoring was paused for some periods to allow for building work, and to fit the insulation.

\subsection{Relative humidity, temperature and heat flux measurements}

Onset UX100-023 hobos were used to measure relative humidity $(\mathrm{RH})$ inside the brick walls. These include combined capacitance humidity sensors and thermistors by Sensirion, located outside of the logging part of the device [8]. The sensors measure humidity between $10 \%$ to $90 \% \mathrm{RH}$ with an accuracy of $\pm 2.5 \%$ which increases to $\pm 3.5 \%$ over $95 \% \mathrm{RH}$, and temperature between $-40{ }^{\circ} \mathrm{C}$ to $75^{\circ} \mathrm{C}$ with an accuracy of $\pm 0.2^{\circ} \mathrm{C}$ between $0{ }^{\circ} \mathrm{C}$ and $50{ }^{\circ} \mathrm{C}$. The sensing element is a polymer,

\footnotetext{
* Corresponding author: n.grint@ucl.ac.uk
} 
which is protected by the liquid crystal polymer housing, with epoxy protecting the connections, all mounted on a glass-reinforced printed circuit board [9]. The sensor casings were trimmed back to minimise the quantity of additional material inserted into the wall.

Figure 1 shows horizontal sections through walls A, B and $\mathrm{C}$. Walls $\mathrm{A}$ and $\mathrm{C}$ are shown with insulation (middle and right), further detail about the insulation build ups are given in section 2.4. The hobo sensors were inserted into three holes drilled diagonally, at a $45^{\circ}$ angle into all three walls, in order to limit damage or disruption to the material in the assumed direct moisture transport path, normal to the wall surface (centre line in figure 1). The perpendicular depths of the sensors from the inside brick surface were $50 \mathrm{~mm}, 175 \mathrm{~mm}$ and $245 \mathrm{~mm}$, in all cases $\pm 5 \mathrm{~mm}$. To avoid advective moisture or heat transfer through air gaps the holes around sensors were packed in with brick dust. The sensors are still able to detect humidity levels in this condition [10].

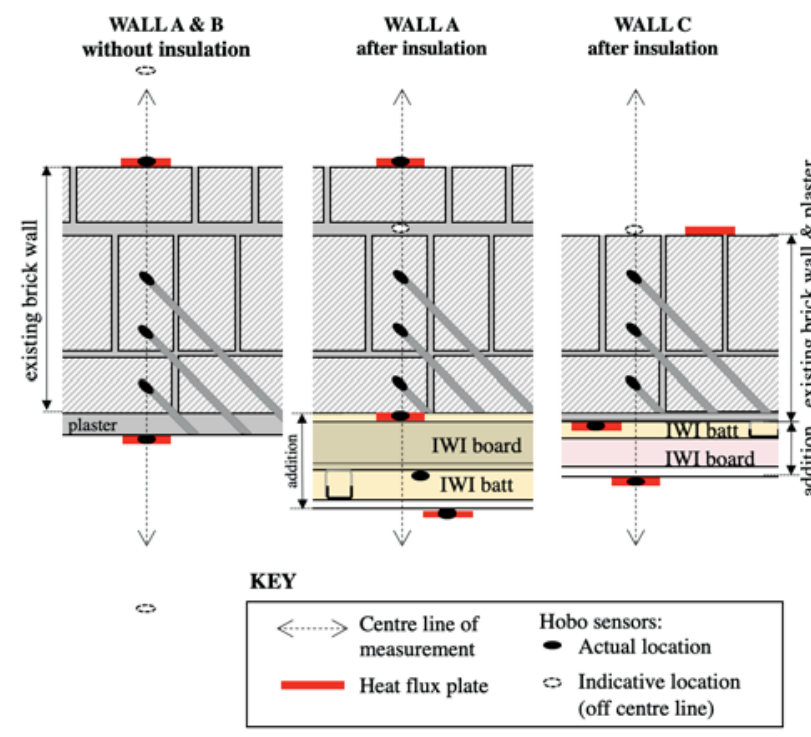

Fig. 1. Horizontal sections of the three walls showing sensor locations.

Images of the sensor installation process are shown in Figure 2. The sensors were inserted via a half plastic tube filled with brick dust and then gradually topped up with more brick dust, this process took at least two hours to ensure the deepest holes were completely filled. Inserting wet clay or mortar may have been quicker, but the sensors would need to be protected from the initial moisture content, and any additional sheathing would add uncertainty to the measurement. The holes were then capped with mortar. To avoid the heat flux plate interfering with the assumed perpendicular flow of heat and moisture through the centre line, three heat flux plates were mounted centrally on bricks adjacent to the centre line, to monitor the same configuration of materials through the wall and to compare the difference between locations. The plaster on part of the inside face of the wall was stripped back in order to locate the brick and mortar joints and a position in the centre of a brick was chosen as the central line of measurement.
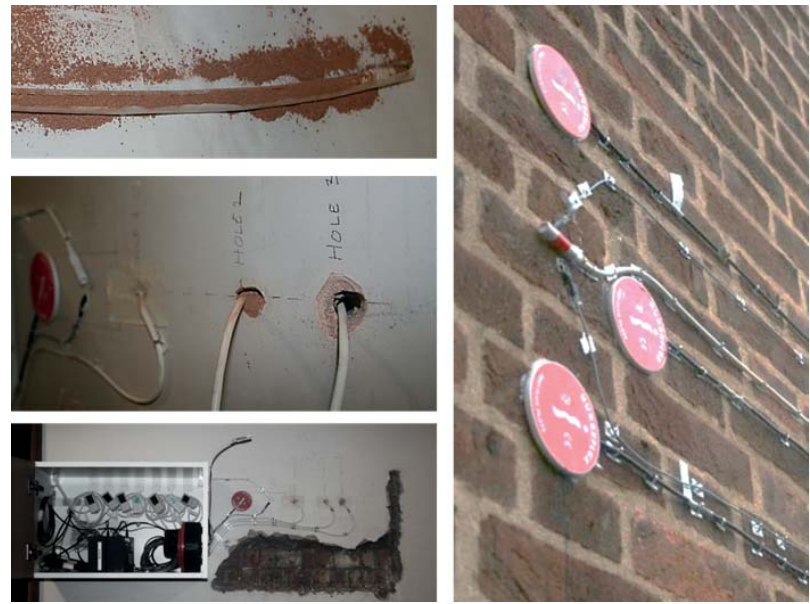

Fig. 2. Installation of the hobos in the wall. Anti-clockwise from top left: hobo sensor in half tube filled with brick dust, packing brick dust into diagonal holes in wall, measurement equipment on internal surface with some plaster removed, measurement equipment on external surface.

\subsection{Moisture content measurements}

In addition to the embedded RH sensors, moisture content was measured in wall $\mathrm{C}$ from Autumn 2017 using wireless Omnisense Hygrotrac S-160 combined temperature, humidity and moisture content sensors, as used in other studies [11-13]. Screws are used to measure the electrical resistance of the material, which is correlated to moisture content. The temperature and humidity sensor is located in a plastic box containing a transmitter, sending data to a central logger connected via a router hub, which transmits these measurements over a mobile phone GPRS network to an online database that can be accessed remotely via a secure website. The stated equipment accuracy is $\pm 0.3 \circ \mathrm{C}$ at $25{ }^{\circ} \mathrm{C}, \pm 2 \%$ for the RH between $10 \%$ and $90 \%$, and $\pm 1 \%$ for moisture content between $10 \%$ and $25 \%$ [14].

The screws can be installed directly into the brick or into timber embedded in the wall. The timber block method assumes that the timber comes into equilibrium with the surrounding wall, and that the moisture content may be used as a proxy for the moisture content of the wall itself. The advantage is that the sensors are calibrated to timber, and the relationship between electrical resistance and moisture content in inhomogeneous brick walls is less well characterised. As with any embedded material it should be noted that the sensors only measure a very local area, and that although this is an indicator of conditions in the element, the sensor itself may change the properties of the adjacent construction [15]. Six hygrotracs were installed in wall $\mathrm{C}$, four directly into the plaster / brick and two into embedded timber blocks. Sensors were cross calibrated in the internal environment.

\subsection{Climate measurements}

Climate monitoring equipment was installed on wall B in Summer 2018 as shown in figure 3. On the left, a Vector A100R anemometer measures wind velocity. The threecup rotor turns a magnetic actuator, and the pulse per 
revolution is transmitted to a wireless datalogger. The Anemometer operates at a maximum speed of $>75 \mathrm{~ms}^{-1}$, with an accuracy of $1 \%$ for readings between 10 and $55 \mathrm{~ms}^{-1}$, and $2 \%$ for readings $>55 \mathrm{~ms}^{-1}$ [16].

The Rain-o-Matic small rain gauge, is a tipping bucket held in place by a hard ferrite magnet, which breaks a circuit and allows the measuring bucket to empty in one quick movement (less than $300 \mathrm{~ms}$ ) and then return to its normal position [17]. The device is simple but can be blocked by debris. The Hydreon RG-11 is an optical rain gauge, which logs interruptions on a light source on the lens cover caused by rain drops. The Hydreon $R G-11$ is a useful qualitative sensor, but no accuracy specification has been derived by the manufacturers due to difficulties in finding a clear correlation with tipping bucket measurements. The sensor will frequently record quantities close to the tipping bucket, but outlier events deviate much further [18].

The Kipp and Zonen CMP3 pyranometer measures global short-wave radiation in the spectral range of 300 to $2800 \mathrm{~nm}$ and has a total daily uncertainty of < $10 \%$ [19]. The Apogee SP110 silicon-cell pyranometer only measures a portion of the solar spectrum (350-1100nm) and is calibrated to estimate the global shortwave radiation from this [20].

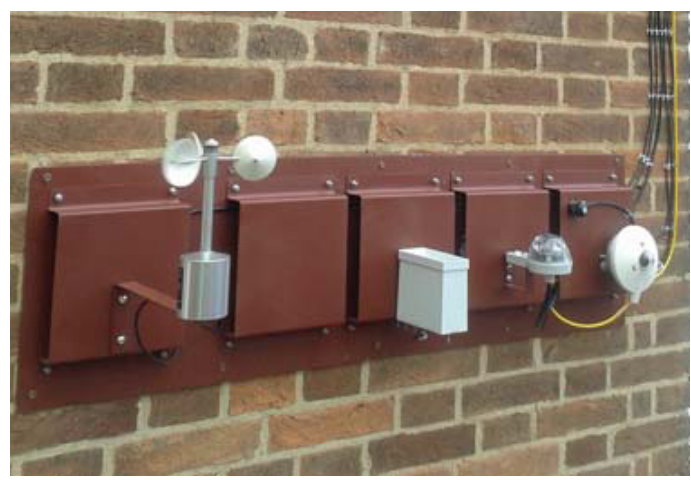

Fig. 3. Climate monitoring equipment. L to R: Vector A100R anemometer, Pronamic Rain-o-Matic tipping bucket rain gauge; Hydreon RG-11 optical rain guage; Apogee SP110 silicon-cell pyranometer; Kipp and Zonen CMP3 pyranometer.

\subsection{Internal wall insulation}

Figure 4 shows the process of installing the internal wall insulation on wall $\mathrm{A}$, which comprised one $100 \mathrm{~mm}$ layer of woodfibre board, fully adhered to the existing brick surface, $50 \mathrm{~mm}$ of woodfibre batt between aluminium brackets and a plasterboard finish. The sensor cables were routed away from the line of measurement and through the woodfibre board, woodfibre batt and plasterboard, along with the cables from the external monitoring equipment, which were also further away from the line of measurement. Interstitial sensors were fixed to the brick face and between the woodfibre board and woodfibre batt.

Wall $\mathrm{C}$ is a similar structure to $\mathrm{A}$ and $\mathrm{B}$, but without the outer layer of brick. The same process was followed, and the sensor depths were the same in the brick wall, but in this case the insulation system was plasterboard on $50 \mathrm{~mm}$ polyurethane mounted on $25 \mathrm{~mm}$ battens (see figure 1), and the voids packed with mineral wool. The installation process is shown in figure 5. The existing plaster was not removed on wall $\mathrm{C}$.
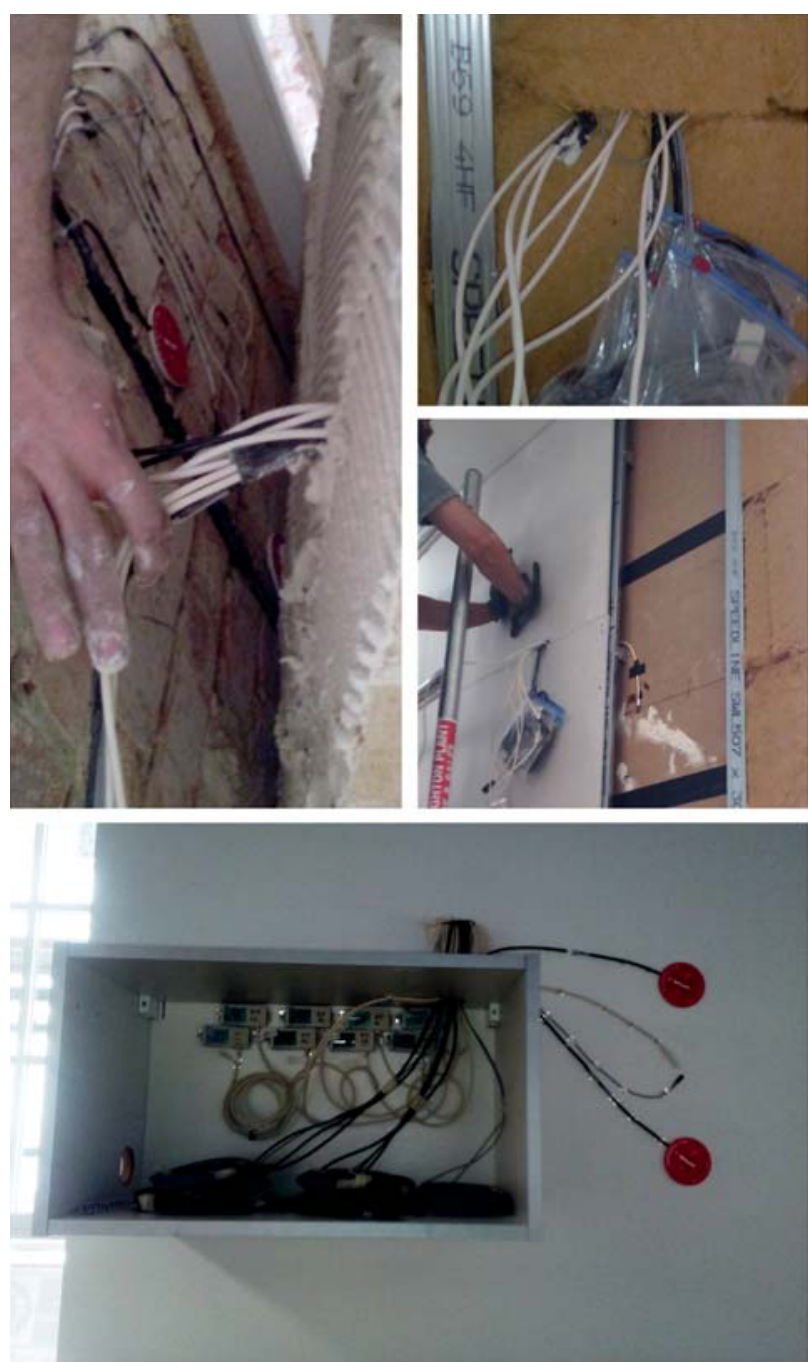

Fig. 4. Installing the IWI on Wall A. Clockwise from top left: surface sensors on brick surface after plaster removed, with cables arranged through the adhesive fixed IWI board away from centre line of measurement; sensor cables fed through IWI batt between aluminium battens; sensor cables fed through fermacell board on metal battens on board (and showing IWI board surface sensor); sensors fixed to new wall surface and cables through to new cupboard, off the centre line of measurement.
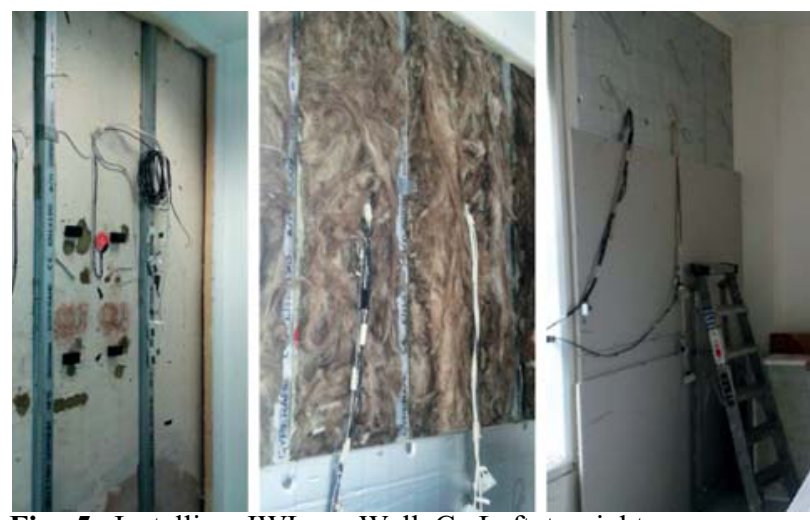

Fig. 5. Installing IWI on Wall C. Left to right: sensors on existing wall; mineral wool fitting between aluminium battens; phenolic insulation board being fixed to battens. 


\section{Results}

\subsection{Overview of humidity data}

Figure 6 shows the relative humidity data for the three walls. The conditions indicated by the numbers are explored in this paper: 1) walls A and B uninsulated over one year, 2) wall B uninsulated over four years including a winter without heating or windows, 3) Wall A insulated and wetting event occurred, 4) wall $\mathrm{C}$ insulated and hygrotrac sensors installed. The most complete and highest resolution dataset was captured in the first 18-24 months for walls $\mathrm{A}$ and $\mathrm{B}$, when five minute data was measured by seven sensors in walls A and B; there are few gaps. From mid-end 2017 the ambient sensors were moved to another in-wall position for walls $\mathrm{A}$ and B, corresponding with the time that wall A was insulated. The heating was switched off in zone A in January 2017, and zone B was unheated for winter 2017/2018 until the beginning of February 2018.

\subsection{Uninsulated walls in 2016}

From Nov 2015 to the end of 2016 both walls A and B were uninsulated and there is comparable data for both, from sensors placed as shown in figure 1. For wall A, there are 420 days of data from at least six sensors, with 6 small gaps in the data representing $1 \%$ of the period; the longest gap is 66 hours. For wall B there are 425 days of data from at least six sensors, with 3 gaps in the data, representing $2 \%$ of the period, the longest gap is 6.4 days. There are 420 days of concurrent data from both walls, from 12-14 sensors with six gaps in the data representing $2 \%$ of the period, the longest gap being 6.4 days. These periods also include surface and ambient data as shown in figure 6 .

Figure 7 shows the RH, vapour pressure and temperature measurements from the 7 sensors across wall $\mathrm{B}$ in 2016. The 5-minutely data is presented as one hour rolling averages for the in-wall $\mathrm{RH}$ data, and seven day rolling averages for the surface and ambient RH data, the temperature and vapour pressure data are all presented as seven day rolling averages. This shows the low frequency trends more clearly but also leads to over-representation of gaps in data in the plots.

During 2016 there is a peak in RH during the summer measured by the in-wall sensors, which does not appear in any other year of data measured, except where walls were insulated mid-year. This may have been caused by the high rainfall during June 2016. The removal of plaster from the inside wall surface (approximately 200mm away from the line of measurement) may also have had an impact, although a sensitivity analysis based on this wall suggests that a reduction in vapour resistance of the plaster and finishes would have the opposite effect [21].

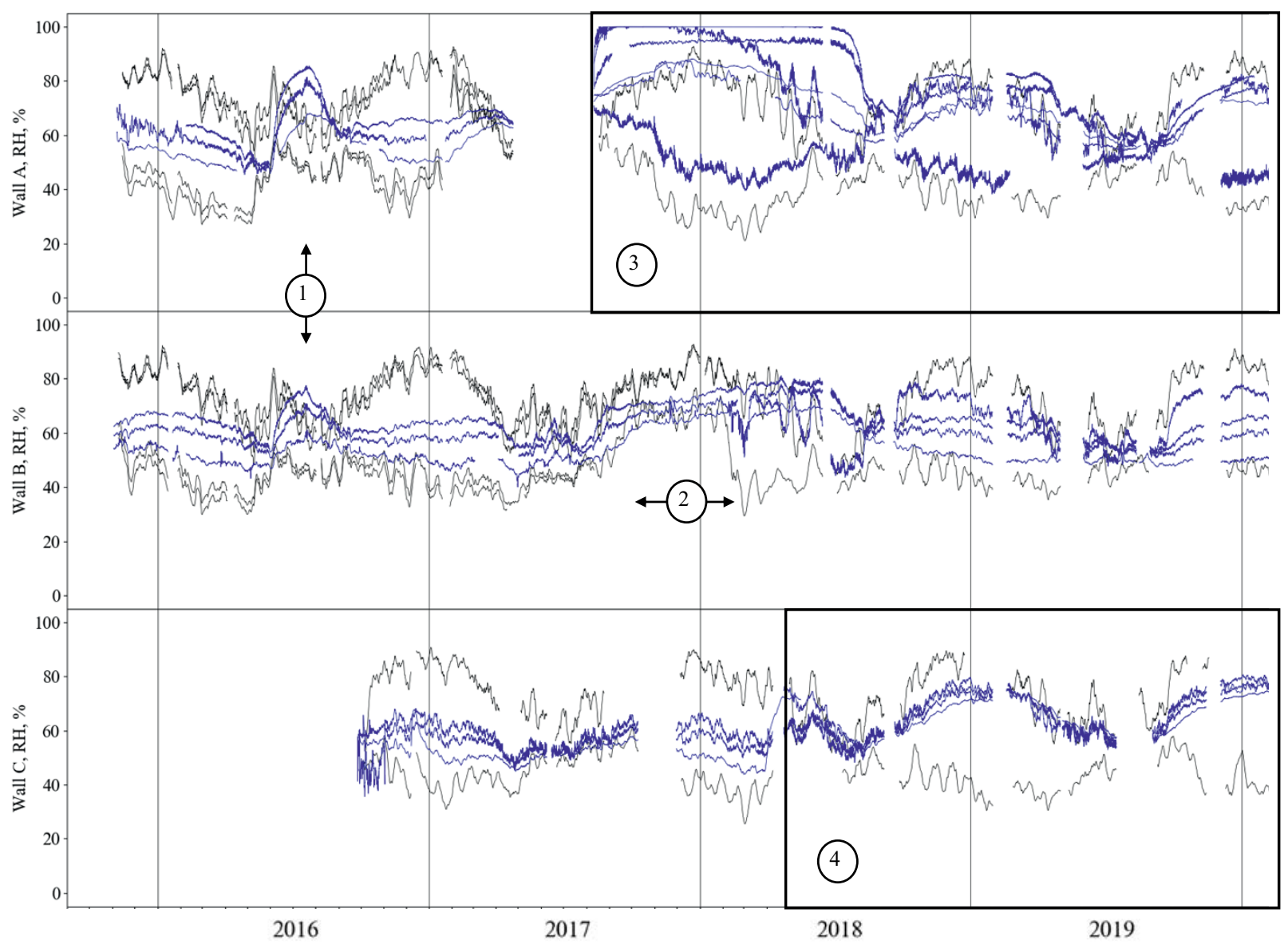

Fig. 6. Relative humidity data for three walls between November 2015 and February 2020. Black shows ambient and surface measurements (seven day rolling average), blue shows in-wall measurements (24hr rolling average. The thick outlines indicate when walls $\mathrm{A}$ and $\mathrm{C}$ were insulated. 

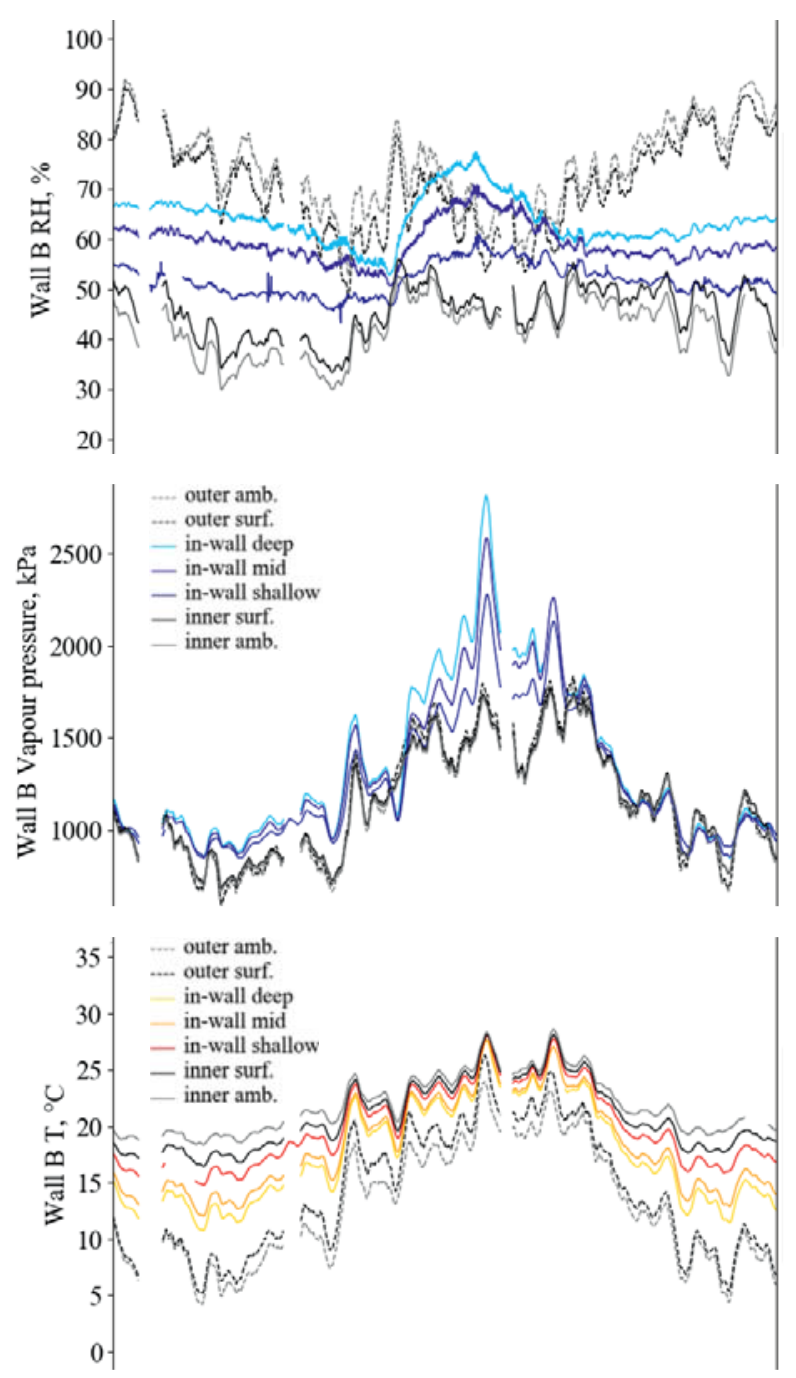

Jan 'Feb Mar' Apr May' Jun 'Jul 'Aug 'Sep 'Oct Nov' Dec

Fig. 7. Measurements of RH (top) vapour pressure (middle) and temperature (bottom) across wall B. Colours available online.

The outside surface and boundary conditions are very similar for walls A and B, varying by a maximum of only $3 \% \mathrm{RH}$ during the year. The inside surface and boundary conditions are more variable. Both rooms have a very low humidity load with an internal vapour pressure excess $\left(\mathrm{p}_{\mathrm{i}}-\mathrm{p}_{\mathrm{e}}\right)$ of less than $200 \mathrm{~Pa}$ at all times of the year, corresponding to ISO 13788 Humidity class 1 (unoccupied buildings, storage of dry goods) [22], although both are used as offices. During this time wall A was in a much smaller room with a single occupant and wall $\mathrm{B}$ in a large shared space. Both walls have radiators approximately $1.5 \mathrm{~m}$ below the sensors, which are controlled by the occupants. Wall $\mathrm{A}$, in a room with single occupation and generally higher temperatures, experienced lower relative humidity than wall B in the winter but higher in the summer.

For both walls the difference between ambient and surface RH is greater at the inside compared to the outside in winter, and greater at the outside compared to the inside in summer as shown in figure 8, which is the opposite for the temperature, as shown in figure 7 . This data is useful for studying the heat transfer and vapour diffusion exchange at the surfaces, and potentially deriving the exchange coefficients. Accompanying heat flux data is also available for walls $\mathrm{A}$ and $\mathrm{B}$ for the 4 years.

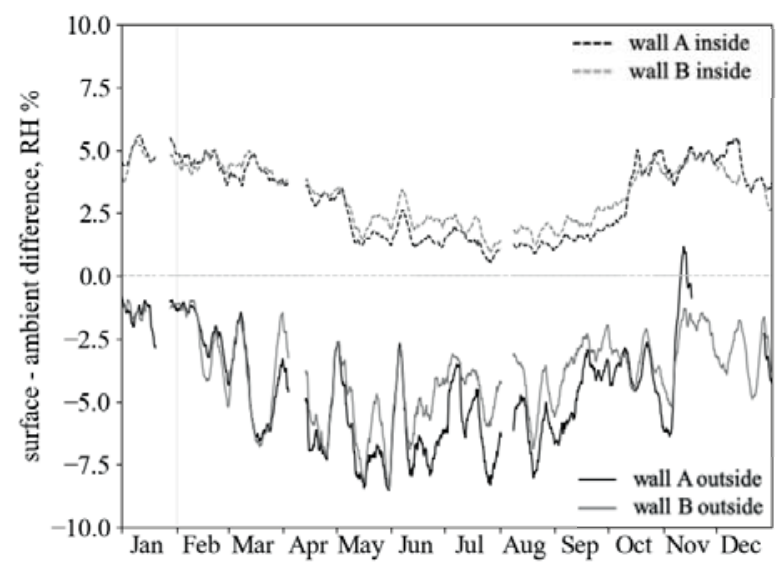

Fig. 8. Difference between surface and ambient RH during 2016.

\subsection{Wall B - uninsulated for 4 years}

Wall B was uninsulated for the duration of the measurements, as a control wall, and the contained space was unheated for the winter 2017/2018 until the beginning of February 2018. The windows were also removed and replaced during this period and the difference between internal and external conditions was reduced to less than $5^{\circ} \mathrm{C}$ in Jan 2018 , compared to approximately $15^{\circ} \mathrm{C}$ in zone A. Figure 9 shows RH from the in-wall sensors over the four years. Figure 10 shows moisture gradients across wall B on July $15^{\text {th }}$ at $12 \mathrm{pm}$ for the four different years, including the surface sensors on both sides of the wall, after 2017 the ambient sensors were removed, and sensors were added to the mortar fill layer. Error bars show equipment accuracy $( \pm 2.5 \%)$ and dimensional uncertainty $( \pm 7 \mathrm{~mm})$.

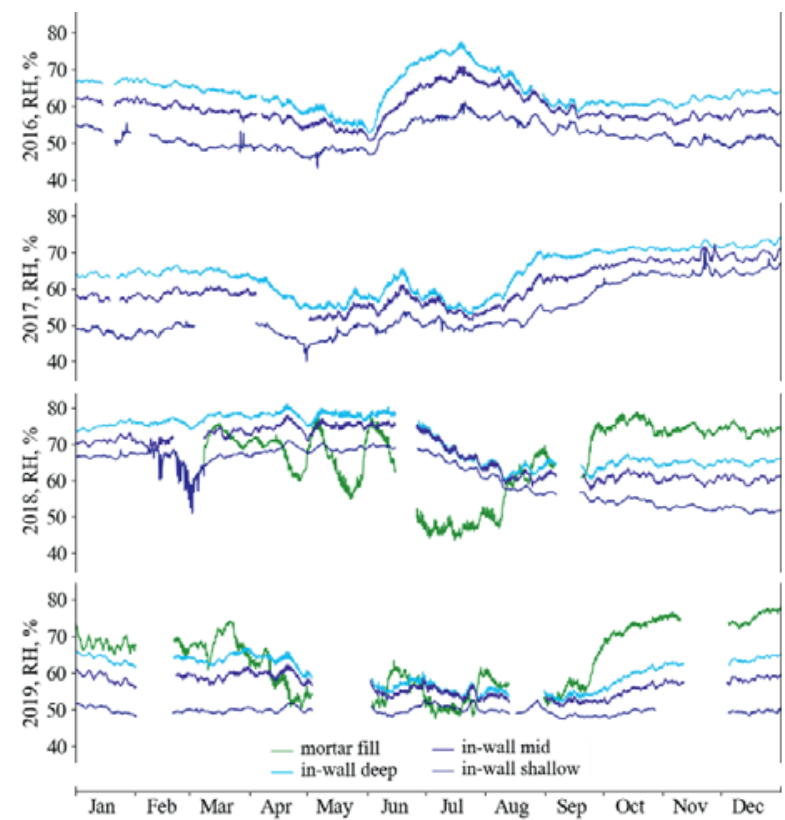

Fig. 9. RH across wall B 2016 - 2019 (top to bottom).

\footnotetext{
* Corresponding author: n.grint@ucl.ac.uk
} 
In 2016 there is a RH peak in summer that is not seen in the other years, and the relative humidity levels are significantly higher in the outer wall $(\mathrm{B} 5,+245 \mathrm{~mm})$. This reduces during the following summer by at least $20 \% \mathrm{RH}$. The external $\mathrm{RH}$ is approximately $10 \% \mathrm{RH}$ less at the same day and time. During summer 2017, following the winter with no heating and windows, the RH through the whole wall is above $65 \% \mathrm{RH}$ but drops to approximately $50 \%$ by the following summer. The external surface $\mathrm{RH}$ is $40-50 \%$ for all four years. The in-wall $\mathrm{RH}$ difference between 2016 and 2019 is notable and may be caused by a combination of the plaster repair, windows being replaced, and differences in external RH.

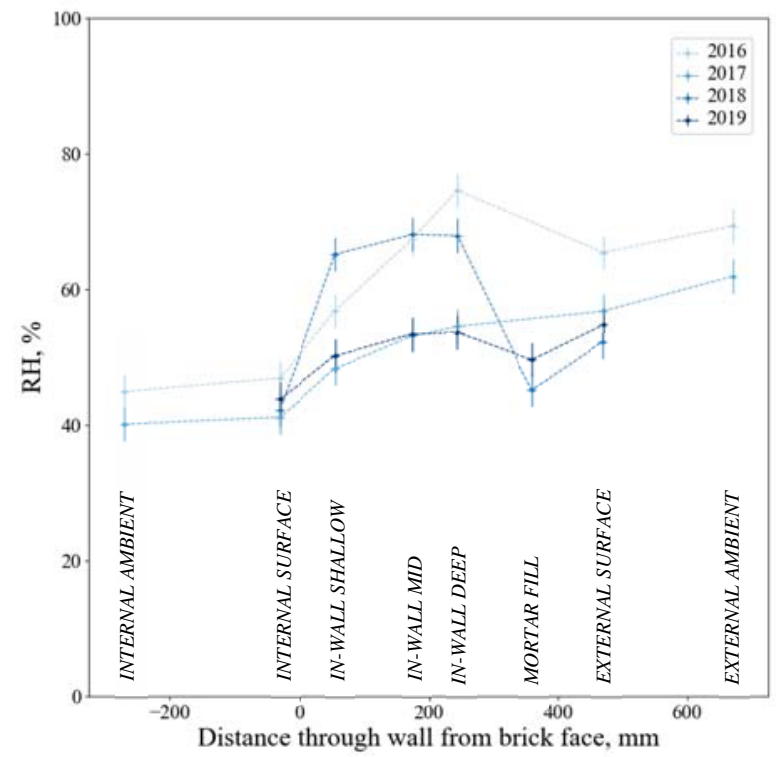

Fig. 10. Moisture gradients through wall B in 2016, 2017, 2018 and 2019 at $12 \mathrm{pm}$ on 15 th July.

\subsection{Internally insulated wall A}

Figure 11 shows the RH measured by the in-wall sensors in wall A and wall B from Aug 2017 to February 2020, after wall A was insulated. Figure 12 shows moisture gradients across both walls including the surface sensors on both sides of the wall in winter 2018/2019 and in summer 2019. Unfortunately, the external surface RH sensor was damaged on wall A after the insulation works, so the measurement at wall $\mathrm{B}$ is used as a proxy. The wall was washed after the IWI was installed which raised the in-wall $\mathrm{RH}$ at location A5 ( $+245 \mathrm{~mm})$ to $100 \%$ from Aug 2017 until June 2018, when this reduced to less than $70 \%$ RH within a few weeks. During this period the RH measured in the organic insulation layers did not rise above $80 \%$ for any significant period of time. By winter 2018/19 the difference between in-wall RH for the sensors in the brick had dropped to approximately $20 \%$, and $10 \%$ by summer 2019 .

Fig. 11 shows the RH levels are higher in the wall at 'in-wall deep' location $(+245 \mathrm{~mm})$. compared to the 'mortar fill' location $(+360 \mathrm{~mm})$ for most of period until September 2019, for the insulated wall, whereas for the control wall (wall B) the in-brick sensors measure lower RH levels than the mortar fill for all of winter 2018/2019 and some of the summer 2019. There is likely to be some air movement in the mortar fill layer, so the conditions follow that of the external environment more closely.

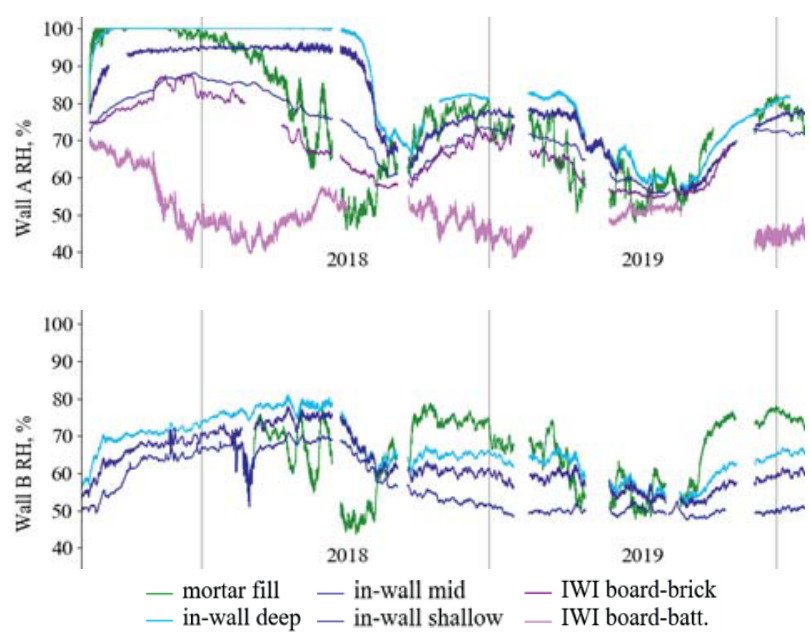

Fig. 11. RH across insulated wall A (top) and uninsulated wall B (bottom) from Aug 2017 to Feb 2020.

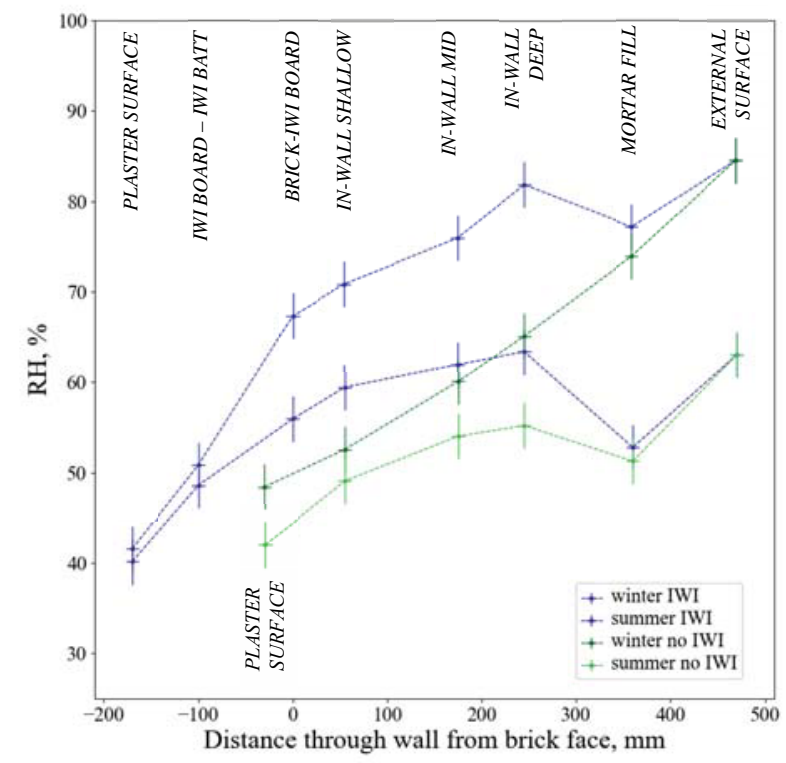

Fig. 12. Moisture gradients through walls $A$ (blues) and $B$ (greens) on $10^{\text {th }}$ Dec 2018 and $10^{\text {th }}$ June 2019 at $12 \mathrm{pm}$.

Figure 13 shows bi-monthly RH gradients through wall $\mathrm{A}$ from the time of the wall being insulated and the external bricks being washed, to the end of 2019, by which time the RH had returned to lower levels. Following wetting, outer locations of the wall reached $100 \%$ RH within a few weeks (although it should be noted that sensor measurement uncertainty increases to $\pm 3.5 \%$ over $95 \% \mathrm{RH})$. The RH measured in the mortar fill layer then falls over the next 6 months, with the gradient increasing gradually, before the measurements become more closely linked to external conditions. The RH levels in the middle brick change by less than $2 \%$ over at least 7 months and drop suddenly during summer 2018.

This data provides the opportunity to investigate the wall recovery from a significant wetting event across different materials at different locations in the wall, to compare estimated parameters for wet and dry conditions 
and to use these, or measured material properties, to compare the data to a hygrothermal model of the same wall. It is also possible to draw some conclusions about anticipated drying times of the system used but it is impossible to separate the effects of adding moisture and insulating the wall as the exact quantity of liquid added is not known.

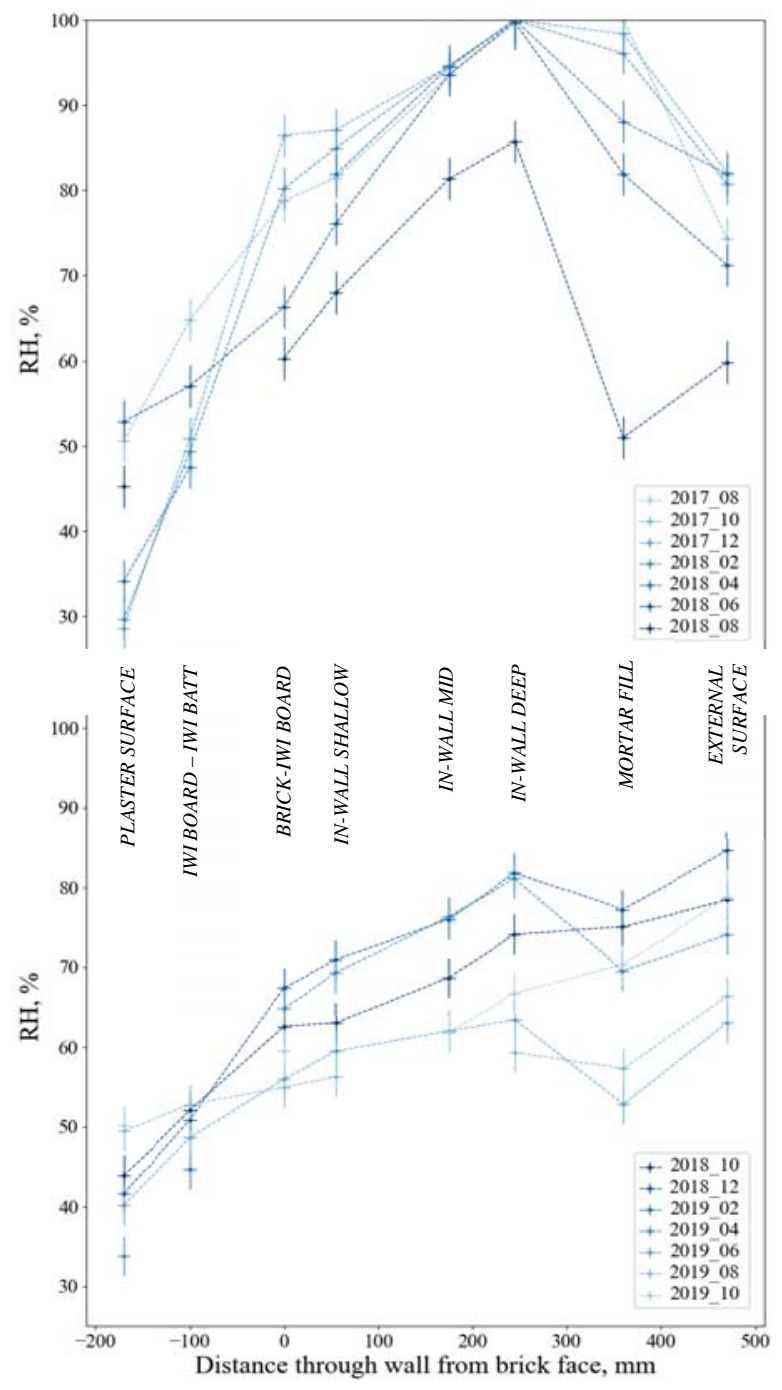

Fig. 13. Bi-monthly moisture gradients through wall A for the year after the 'wetting event' (from Aug 2017 to Aug 2018, top) and the following year (Oct 2018 to Oct 2019, bottom).

\subsection{Internally insulated wall C}

Wall $\mathrm{C}$ is thinner, and has a different insulation system to walls $\mathrm{A}$ and B, as described earlier. Figure 14 shows the in-wall RH measurements for wall C for 2017, 2018 and 2019. The wall was insulated in spring 2018, and at the same time the hygrotrac sensors were installed - 14 months of this data are shown as dotted grey lines in figure 14 for five of the sensors. One of the hygrotracs was embedded in wet mortar in the wall which added moisture, no additional moisture was added as the insulation was dry fixed. When the insulation was installed the original surface sensor became an interstitial sensor between the brick and the mineral wool insulation and additional sensors were added to the new surface.
This increase in moisture is seen most clearly in the data from the hygrotrac installed in the timber block and embedded in mortar, and this reduces to below the level measured by the other hygrotrac sensors by the end of the summer. The range of measurements for the other sensors is less than 7\% RH by May 2019, which is slightly more than the sensor accuracy $(2.5 \% \mathrm{RH})$. There two periods of unexplained fluctuations on the readings from two of the sensors. It should be noted that the equipment uses the resistance to moisture content correlation for timber, so the measurements in the brick can only be used to assess trends and not absolute MC. There will also be some differences due to the depths and different moisture retention curves for the materials.

The high frequency RH fluctuations measured by the interstitial sensor are comparable to the brick-IWI board interstitial conditions measured in wall $\mathrm{A}$, despite this sensor being in the adhesive layer fixed behind a rigid board. In wall $\mathrm{C}$ the interstitial RH is generally higher than the mid in-wall measurement, and all in-wall measurements are tightly grouped, whereas in wall A the outside of the wall is significantly wetter. In 2019 the interstitial RH is generally less in wall A than wall C, but wall $\mathrm{C}$ may not be fully dried out at this time.
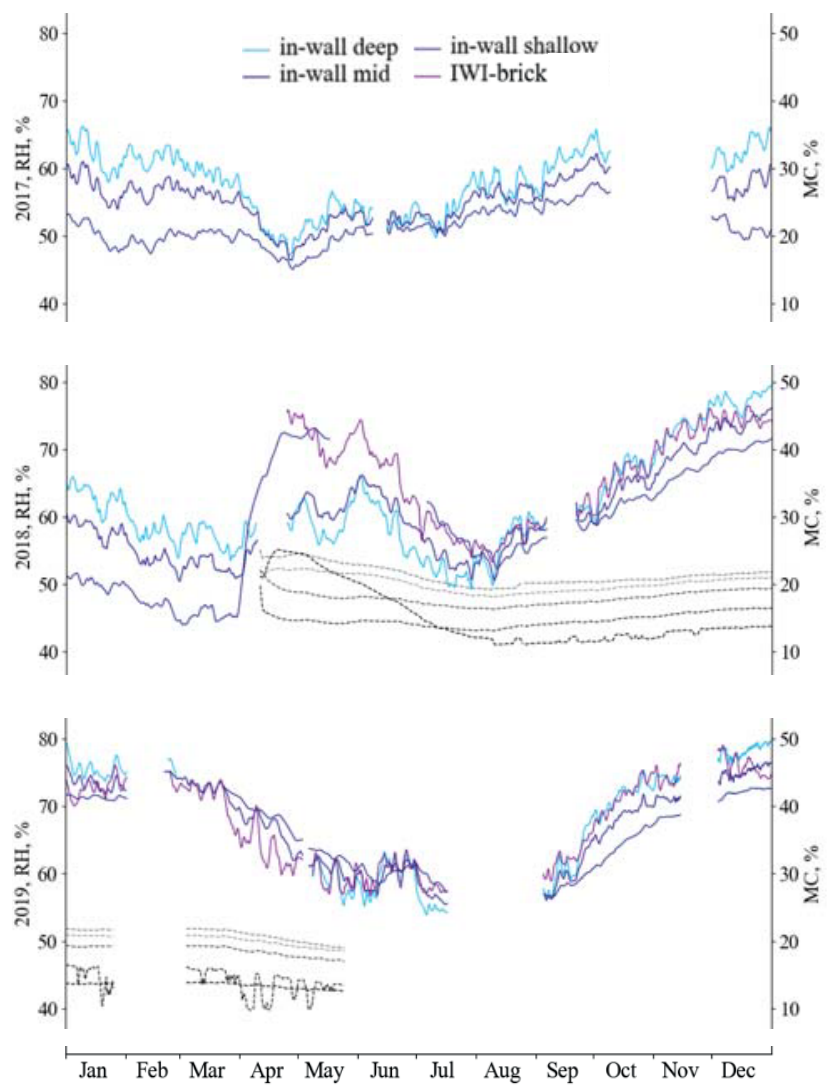

Fig. 14. RH across wall $\mathrm{C}$ in 2017, 2018 and 2019 (top to bottom). The dotted grey lines show MC measurements, top to bottom: bottom right sensor; bottom left sensor; top left sensor; top right sensor; mid left sensor in timber block.

\subsection{Climate data}

Figure 15 shows the climate data collected at the external face of Wall B for 18 months, from June 2018 to 
December 2019. This data offers the opportunity to assess the wall's response to external conditions in more detail during this period, and through comparison to local weather data can offer an insight into local sheltering. It also allows comparison of two different pyranometers and two different rain sensors. The collection method does not include a wind driven rain collection plate [23], but horizontal rainfall immediately adjacent to the surface may be a useful comparison to WDR calculations using local weather data available [21].

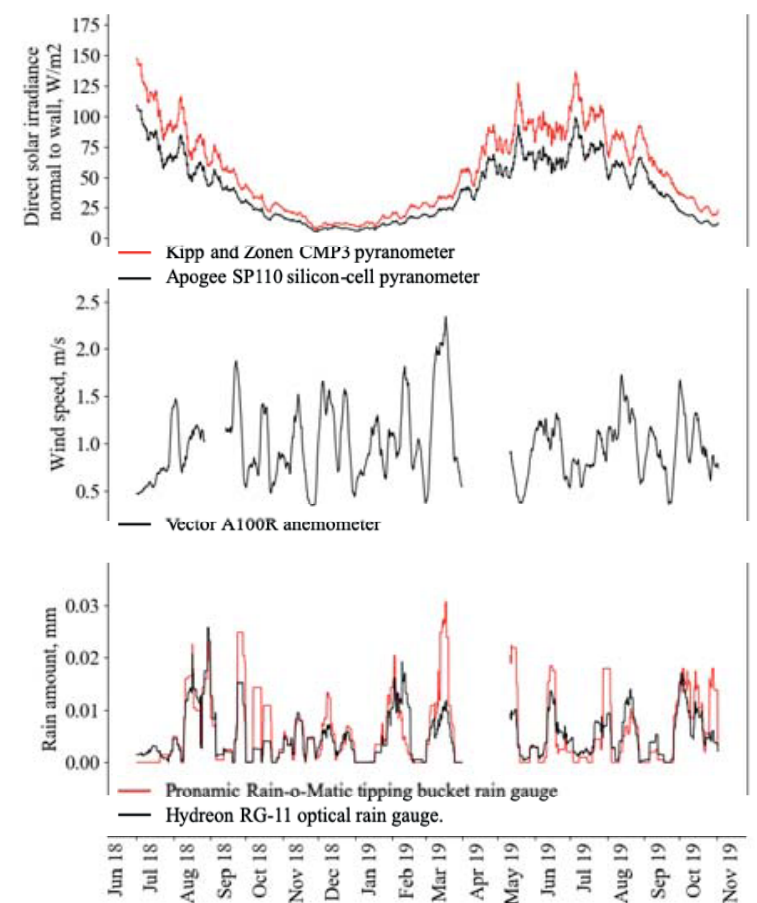

Fig. 15. Climate data from June 2018 to Dec 2019. Top to bottom: Solar irradiance; wind velocity; rain amount.

\section{Conclusion}

This paper provides an overview of the in-wall $\mathrm{RH}$ data available for three walls and discusses some potential studies for which the data can be used. Additional supporting data is introduced from the hygrotrac sensors and climate monitoring equipment, and further data from heat flux plates and thermistors is also available.

The dataset provides high resolution measurements over long uninterrupted periods and over multiple years, giving the opportunity to study a range of conditions and the impacts of changes to the environment. The impact of wall insulation was recorded in two walls, with one control wall, and with the addition of an external surface wetting event. The results highlight the difference in performance of the two wall structures, with differences in mid-wall voids potentially an important factor. They also demonstrate the multi-year recovery period for a wall subjected to high pressure washing; the long-term high humidity experienced after this event did not cause damage this wall, but could cause problems for walls of different structures, and subjected to colder winters.

The data presented in this paper is published online for the use of the research community. The high number of measurement points throughout the walls gives the opportunity to use the data set for parameter estimation by inverse analysis, for walls under different moisture loads. The multiple in-wall sensors also provide the opportunity to test simplified models of a reduced number of physical processes, representing isolated parts of the wall.

\section{References}

1. Committee on Climate Change (2019)

2. H Rafidiarison, R. Rémond, E. Mougel, Building and Environment 89, 356-368 (2015)

3. C. Strangfeld, S. Kruschwitzab, Construction and Building Materials 177, 511-521 (2018)

4. T. Busser, A. Piot, M. Pailha, S. Rouchier, M. Woloszyn, 11th Nordic Symposium on Building Physics, Energy Procedia 132, 747-752 (2017)

5. T. Desta, J. Langmans, S. Roels, Building and Environment 46, 1038-1046

6. M. Guizzardi, D. Derome, R. Vonbank, J.Carmeliet, Building and Environment 89, 59-71 (2015)

7. D. D'Ayala, Y. Aktas, Building and Environment 104, 208-220 (2016)

8. Abdul, H. Wallentén, Building and Environment 123, 351-362 (2017)

9. Sensirion, Datasheet (2011)

10. Sensirion, Pers Comms (2015)

11. S. Fortinoa, P. Hradil, A. Genoese, A. Genoese, A. Pousette, Construction and Building Materials 208, 492-505 (2019)

12. C. Capener, E. Sikander, 6th International Building Physics Conference, Energy Procedia 78, 34583464, (2015)

13. L. Gullbrekken, S. Geving, B. Time, I. Andresen, 6th International Building Physics Conference, Energy Procedia 78, 219 - 224 (2015)

14. Omnisense hygrotrac S-160 (no date)

15. D. Derome, A. Teasdale-St-Hilaire, P. Fazio Buildings VIII/Wall Performance-Practices (2001)

16. Campbell Scientific Ltd, A100R Switching Anemometer User Manual (2010)

17. Pronamic, Rain-O-Matic Small Rain Gauge Technical specifications (no date)

18. Hydreon corporation, Model RG Optical rain guage website and Pers Comms (2016)

19. Kipp and Zonen, CMP series pyranometer manual (2016)

20. Apogee instruments, SP-110 pyranometer manual (2016)

21. N. Grint, V. Marincioni, C. Elwell. 12th Nordic Symposium on Building Physics (2020 - partner paper by the same author)

22. EN-ISO 13788 Hygrothermal performance of building components and building elements.

23. B. Blocken, J. Carmeliet, Building and Environment 41(12), 1798-1810 ( 2006) 